\title{
A promessa do audiovisual interativo
}

\author{
The promise of interactive audiovisual
}

João Baptista WINCK'

\section{RESUMO}

A cadeia produtiva do audiovisual utiliza o capital cultural, especialmente a criatividade, como sua principal fonte de recursos, inaugurando o que se vem chamando de economia criativa. Essa cadeia de valor manufatura a inventividade como matéria-prima, transformado idéias em objetos de consumo de larga escala. A indústria da televisão está inserida num conglomerado maior de indústrias, como a da moda, das artes, da música etc. Esse gigantesco parque tecnológico reúne as atividades que têm a criação como valor, sua produção em escala como meio e o incremento da propriedade intelectual como fim em si mesmo. A industrialização da criatividade, aos poucos, está alterando o corpo teórico acerca do que se pensa sobre as relações de trabalho, as ferramentas e, acima de tudo, o conceito de bens como produto da inteligência.

Palavras-chave: indústrias criativas; audiovisual digital; televisão interativa; cadeia produtiva.

\section{A B STR ACT}

The productive chain of audiovisual uses the cultural capital, especially the creativity, as its main source of resources, inaugurating what is being called creative economy. This chain of value manufactures the inventivety as raw material, transforming ideas into objects of consumption of wide scale. The television industry is inserted in a bigger conglomerate of industries, such as fashion, arts, music, etc. This gigantic technological park congregates the activities that hold the creation as a value, its production in scale as a means, and the increment of the intellectual property as an end in itself. Little by little the industrialization of the creativity is modifying the theoretical body regarding what's thought about work relations, the tools and, above all, the concept of properties as product of intelligence.

Keywords: creative industries; digital audiovisual; interactive television; productive chain.

\section{A CULTURA AUDIOVISUAL}

Está longe o dia do consenso sobre a problemática da democratização do acesso aos meios de produção de mensagens. Tampouco há perspectiva sobre a criação de um modelo institucional diferente do que está em vigor, embora a discussão sobre a regulamentação do sistema digital esteja urgente na pauta. A discussão vem acirrando a disputa entre órgãos reguladores, governo, setor privado e os interesses mais gerais da população.

\footnotetext{
1 Docente, Departamento de Comunicação Social, Faculdade de Arquitetura, Artes e Comunicação, Universidade Estadual Paulista. Engenheiro Luiz Edmundo Carrijo Coube, s/n, Vargem Limpa, 17033-360, Bauru, SP, Brasil. E-mail: <winck@uol.com.br>. Recebido em 8/1 1/2006 e aceito para publicação em 27/7/2007.
} 
E o acirramento não é em vão. As tecnologias de comunicação, cada dia mais capazes, estão abrindo novas fronteiras para o conjunto da cadeia produtiva, desde a indústria de base até a de conteúdos culturais, educativos e de entretenimento, entre outros setores.

Apesar da revolução tecnológica que a TV digital está prometendo, a regulamentação do novo sistema de comunicação não prevê uma revisão profunda nos modos de realização social da informação, como se apregoa. No contexto das comunicações, onde global e local romperam fronteiras por meio da mídia, a questão da produção regionalizada de conteúdo audiovisual exige urgência. Regulamentar as ações locais é a melhor resposta à manutenção da diversidade cultural, da expansão da democracia e do pleno exercício da cidadania.

Neste artigo, entretanto, será abordado brevemente um fenômeno associado ao aumento da capacidade política e das possibilidades tecnológicas dos meios de comunicação, que se vem chamando de economia criativa, cuja discussão tem enfoque na economia do audiovisual como carro-chefe de uma ampla cadeia produtiva emergente.

É consenso que o desenvolvimento vertiginoso da linguagem audiovisual foi um dos maiores fenômenos estéticos e sociológicos no Século XX, derivando para a chamada Cultura Audiovisual.

Ela surge a partir dos desdobramentos dos processos de mecanização das linguagens, da articulação e avanço da indústria da cultura, da informação e do entretenimento e, sobretudo, a partir da crítica sistemática aos pressupostos do pensamento tradicional, levadas a cabo pelas vanguardas estéticas e pela ciência do início do século passado.

Tamanha sua força, a Cultura Audiovisual logo passou a ser percebida como uma matriz dinâmica das maneiras de ser, de estar, de se relacionar e de perceber o mundo. Com isso, as indústrias do lazer, do entretenimento e do mercado de bens simbólicos passaram a movimentar cifras cada vez mais significativas, acumulando poder.

A revolução tecnológica inaugurada pelos meios audiovisuais veio implementar um projeto de sociedade distinto da cultura letrada. A partir de meados do século XX, com a popularização do cinema, do rádio e da TV, a Cultura Audiovisual ganha outras dimensões de complexidade, inaugurando um design de relações incomum entre as pessoas e informações, a chamada era das telecomunicações.

Nesse período, não sem muita crítica, foi notória a sedimentação de atividades criativas e produtivas diferenciadas, que redefiniram os parâmetros de comportamentos éticos em quase todo o mundo. Essas modificações reverberam até hoje naquilo que alguns teóricos definiram como sociedade do espetáculo.

A Cultura Audiovisual passou a ser o foco de alterações profundas no modo de vida, na sensibilidade e na consciência de grande parte das sociedades. A filosofia, as tecnologias e a estética do audiovisual articulam os olhos eletrônicos de um tipo de cultura cuja essência é a superação do natural pelo artificial. Contudo, nas profundezas deste olho eletrônico, desenvolve-se a sociedade do simulacro, da aparência, do consumo da consciência como imagem do eu, do outro e de todos nós sob a influência do liberalismo econômico. Esse tipo de olhar eletrônico passou a moldar o imaginário do Ocidente contemporâneo.

Atualmente o olhar eletrônico do audiovisual tornou-se o centro de gravidade de uma precária gnosiologia dos sentidos e dos sentimentos. As estratégias de imaginar e as táticas de especular amalgamam-se ao registro técnico rumo à unificação dos campos da imaginação ao campo da representação científica da realidade. As imagens simbólicas contemporâneas ganharam sons e movimentos associados ao videográfico, seja no campo da ciência ou da cultura. A chamada "realidade virtual", construída por meio de máquinas, instrumentos e ferramentas geradores de representações audiovisuais, vem galgando os espaços até então ocupados exclusivamente pelas representações gráficas. Cada vez mais os processamentos de representações abstratas são indissociáveis de suas formas de apresentação concreta, por meio do audiovisual, nas telas multifuncionais dos computadores interconectados (Winck, 2007).

A questão de fundo colocada ao pensamento contemporâneo, entretanto, está na constatação de que o observador, seus instrumentos de observação e as maneiras de observar formam uma única e indissociável equação. Os meios de observação interferem no fenômeno, recortando-o e reconstruindo-o a partir do ponto de vista do observador. O projeto do observador define um curso possível para o processo de análise, derivando para a leitura do fenômeno como produto dessa complexa equação. 
Entrementes, a geração de valor, no interior da cadeia produtiva do audiovisual, passou a incorporar elementos intangíveis dotados de valores simbólicos, capazes de gerar valor econômico tangível, por meio da utilização do conhecimento, da criatividade e do capital intelectual como principal fonte de recurso financeiro e, especialmente, das potencialidades de socialização, identidade e soberania nacionais enquanto principais valores econômicos agregados aos meios audiovisuais. A representação audiovisual tornou-se, ela própria, maneira de pensar e agir sobre a realidade.

Mas o fenômeno é maior do que as análises que se poderiam fazer dele neste breve artigo. Só para se ter uma idéia, estima-se que existam mais telespectadores do que a soma dos leitores na história do Ocidente. Calcula-se algo em torno de $70 \%$ dos lares em todo o mundo ligados a pelo menos um aparelho de TV. Isso significa números próximos aos quatro bilhões de pessoas. No Brasil, a cifra sobe para os estrondosos $98 \%$ de lares com $\mathrm{TV}$, o que representa cerca de 140 milhões de pessoas ligadas à TV aberta e mais de três milhões de assinantes de TV paga. Estimase que, das quatro horas de televisão que o brasileiro assiste diariamente, três são produção nacional, das quais duas são ficção (Machado, 2000).

Neste artigo, pretende-se abordar alguns aspectos da reviravolta que está sacudindo a discussão, iá tempestuosa, sobre a Cultura Audiovisual. Reparase a emergência de uma nova organização econômica no campo da indústria cultural: a chamada economia criativa e o fenômeno da virtualização da propriedade.

\section{A economia do audiovisual: criatividade como negócio}

Com o desenvolvimento das tecnologias digitais entraram na ordem do dia os desafios globais derivados do novo tipo de economia que elas engendram.

O mundo digital utiliza o capital cultural, especialmente a criatividade, como principal fonte de recursos, desdobrando a problemática de se implantar e administrar uma cadeia produtiva que manufatura a inventividade como matéria-prima, transformando-a em objetos de consumo de larga escala.

Nessa nova economia, a valorização da atividade criativa é o fator de geração de riqueza, por meio da identificação de tendências, estratégias e medidas que explorem as potencialidades dos agentes produtivos, visando a acumular efetivos industrializados (Guerra, 2002).

Enquanto parque industrial criativo, os meios de produção audiovisuais propiciam emprego e renda, tributos e impostos, atraindo mão-de-obra altamente qualificada em arte, ciência, tecnologia, economia e política, dentre outras áreas do saber. Além disso, a indústria do audiovisual faz alimentar a economia como um todo, sobretudo a economia das idéias e dos signos, pois robustece a opinião pública por meio do realce de determinados valores culturais. Nenhum parque industrial faz isso com tanta competência quanto o do audiovisual e seus produtores associados.

A cadeia produtiva do audiovisual, por sua vez, está inserida num conglomerado maior de indústrias afins, parque industrial genericamente chamado contemporaneamente de "indústrias criativas". Esse gigantesco parque tecnológico reúne todos os ramos de atividades que têm a criação como matéria-prima, sua produção em escala como meio e o incremento da propriedade intelectual como fim em si mesmo.

Estão aglutinados nesse novo conceito os ramos das artes visuais e audiovisuais (além do cinema, televisão, vídeo, inclui-se a publicidade, internet, fotografia, multimídia etc.), do design (de moda, design gráfico, comunicação visual etc.), das artes cênicas (teatro, dança, performance), das artes plásticas (pintura, escultura, arquitetura etc.), da música e demais manifestações artísticas capazes de reprodução em série. A indústria livreira e os meios de comunicação impressos (jornal, revista, manuais etc.), assim como a produção de softwares e produtos digitais fazem parte do parque tecnológico das "indústrias criativas". Ainda entram nessa lista as bibliotecas e museus presenciais e a distância, a indústria do entretenimento, os parques temáticos, exposições e feiras, turismo cultural etc.

Ou seja, as "indústrias criativas" reúnem todas as formas de expressões e mensagens capazes de serem produzidas e reproduzidas em massa por algum tipo de meio de comunicação. A criatividade como matériaprima, nesse aspecto, vem transformando o conceito de propriedade física em bens imateriais dotados de potência para fazer mover a economia como um todo. Esse fenômeno, aos poucos, está alterando o corpo teórico acerca do que se pensa sobre as relações de trabalho, as ferramentas e, acima de tudo, o conceito de bens como produto da inteligência. 
Estima-se que a cadeia produtiva das "indústrias criativas" no Brasil empregue mais de 610 mil pessoas, números maiores que os da indústria automobilística, por exemplo. Aqui, entretanto, essa cadeia produtiva representa apenas $1 \%$ do PIB, enquanto que, em alguns países da Europa, as "indústrias criativas" representam mais que $7 \%$, ou US\$ 1,3 trilhão ao ano, como é o caso da França.

Grosso modo, do volume de negócios e oportunidades que a criatividade como matéria-prima é capaz de gerar, cita-se, por exemplo, a indústria editorial brasileira, que em 2005 faturou $R \$ 2,18$ bilhões, ou seja, 320 milhões de livros vendidos. A indústria cinematográfica nacional, $R \$ 530$ milhões, o que representa 90 milhões de espectadores. $O$ meio fonográfico rendeu um bilhão de reais, o que significa 80 milhões de CDs vendidos ao ano.

Os números são surpreendentes, apesar de o investimento em cultura ainda ser considerado de alto risco e, por isso, modesto no nosso mercado. Estimase que o potencial empregador da economia criativa é 90\% maior que o empenhado nas atividades de fabricação de eletroeletrônico, 53\% superior ao da indústria automobilística e de autopeças juntos e 78\% maior do que o empregado em serviços industriais de utilidade pública, tais como o de energia elétrica, de distribuição de água e esgotos e de equipamentos sanitários. ${ }^{2}$

O dinamismo das "indústrias criativas" tem grande capacidade de envolver outros setores da economia. A associação com a telefonia celular está investindo no desenvolvimento dos videofones, aparelhos de telecomunicação móvel que permitem a transmissão e recepção de sons e imagens. Calcula-se que esse novo mercado para o audiovisual venha a mover em torno de um trilhão de dólares até 2010. Só no Brasil existe o potencial de 58 milhões de usuários de audiovisual via telefones celulares, o que nos coloca na quinta posição no ranking mundial. ${ }^{3}$

Embora altamente concentrada, a produção de audiovisual no Brasil é considerada uma das maiores do mundo, colocando no mercado mais de 50 mil horas anuais de programação, o que faz render cifras beirando os seis bilhões de dólares. Exportamos em média 24 mil horas de programação por ano para 60 países. $O$ volume de exportação de nossos produtos audiovisuais gira em torno de 38 milhões de dólares, sendo considerado muito pequeno frente à importação, que nunca é inferior aos 695 milhões de dólares anuais. ${ }^{4}$

Falar da indústria da televisão significa lidar com números astronômicos, quer sejam de públicos, do volume de capital, de negócios e oportunidades que faz circular, quer sejam dos números de postos de trabalho diretos e indiretos que é capaz de oferecer. Mas aqui esses dados servem mais para demarcar a grandiosidade do problema do que para tabular estatísticas.

Com o fornecimento de TV digital interativa sistema que até 2010 irá substituir o atual parque tecnológico da produção industrial de TV no Brasil avalia-se que os negócios e oportunidades tendam a triplicar até 2020. A associação da televisão ao computador e à telefonia móvel irá permitir que o público acesse uma gigantesca rede global de comunicações. Essa rede interligará residências, empresas, escolas, sindicatos, computadores pessoais, telefones etc. a uma malha de projetistas e prestadores de serviços, de informação e de entretenimento sem precedente na história da humanidade. A previsão é de que a TV interativa, logo no início das operações, oferecerá cerca de 500 diferentes canais de programação, cada um deles gerando por volta de três mil horas anuais de mensagens de todo tipo.

Só para se ter uma idéia do tamanho do mercado potencial, estima-se que cada hora de audiovisual produzido envolva, na menor das hipóteses, em torno de 50 empregos diretos e 200 indiretos, animando toda a cadeia produtiva da economia criativa.

Porém, com o desenvolvimento dos equipamentos e das ferramentas, é possível que o tamanho do cenário da oferta de produtos e serviços

2 conjunto dos dados econômicos citados foi extraído de duas fontes: o Ministério da Cultura. Disponível em: <http:// www.cultura.gov.br> e IBGE. Disponível em: <http://www.ibge.gov.br>. Acesso em: 20 out. 2006.

3 Sobre esse tema confira: Contribuições referentes à Sociedade da Informação. Disponível em: <http://www.telebrasil.org.br/confregion/conf-region.asp>. Acesso em 20 out. 2006, 19:30.

4 Sobre esse tema confira: Diagnóstico governamental da cadeia produtiva do audiovisual. Disponível em: <http://www.cultura.gov.br/ textos/diagnosticoaudiovisual.zip>. Acesso em: 20 out. 2006, 16:30. 
se multiplique por vinte antes da metade do século. As previsões apontam para um mercado mundial de serviços via TV digital interativa que deverá movimentar nada menos do que US\$ 62 bilhões já em 2008. Se computadas as transações de comércio eletrônico e publicidade via TV interativa, estima-se um acréscimo de mais US $\$ 44,8$ bilhões às expectativas de negócios e oportunidades, isso em projeções modestas. ${ }^{5}$

que está realmente em jogo, nas discussões sobre a implantação da TV digital, é o conjunto de oportunidades econômicas que o novo modelo (tecnológico e de negócios) vai abrir para os setores envolvidos. Isso porque, enquanto a discussão tratar das questões meramente tecnológicas, é possível manter o "bom nível" das considerações "objetivas" sobre os negócios e oportunidades. Dessa forma é mais fácil afirmar o que seria mais viável do ponto de vista técnico e de mercado produtor. $\bigcirc$ mercado consumidor viria a reboque, impulsionado e convencido pela publicidade e propaganda.

Não apenas as altas cifras e o conjunto das oportunidades justificam a necessidade do aprofundamento das agendas da pesquisa e das lutas pela democratização da comunicação digital no Brasil. Estamos diante de uma revolução conceitual, ética e estética em larga escala e sem comparação na história. Isso exige esforços redobrados de todos os agentes para compreender as novidades e para elas encontrar respostas elegantes e socialmente responsáveis.

É urgente atinar para uma via de desenvolvimento sustentável da economia criativa, por meio do investimento na ciência, nas artes, nas tecnologias, nos saberes e práticas voltados para a geração de conteúdos audiovisuais.

avanço tecnológico das telecomunicações possibilita a troca de arquivos de imagens, sons e textos a grandes velocidades, facilitando, hipoteticamente, o acesso generalizado às bases de dados culturais, históricos e científicos disponíveis no mundo todo. Entretanto, a novidade posta à cena da cadeia produtiva do audiovisual é a consideração da existência de um interlocutor ativo, reativo e inteligente. Esse novo tipo de público, capaz de respostas, de diálogo e crítica criadora, pode atuar junto aos produtores de conteúdos em linguagem audiovisual digital.
Nesse contexto voltam à cena as polêmicas sobre as políticas de formação de opinião pública e as estratégias de provimento de informações de modo descentralizado e democrático.

Há que se considerar que o modelo de cadeia produtiva centralizada nas mãos de poucos resulta em um tipo de monocultura predatória da opinião de alguns sobre a maioria, cujo resultado é a "ausência produzida" das particularidades.

A paupérie da experiência da exclusão acontece não pela falta de acesso aos meios, mas, sobretudo, pelo colapso das expectativas individuais acerca da possibilidade de informar algo, visto que o discurso hegemônico afirma a existência de um alguém "superior", capaz de realizar conteúdos com mais competência, originalidade e recursos tecnológicos do que os demais.

\section{A inclusão social do telespectador e a democratização dos meios}

A valorização da identidade local e a promoção da participação pública em detrimento das fontes centralizadas de geração de conteúdos homogêneos são os aspectos mais importantes a serem considerados no desenvolvimento da "sociedade do conhecimento". Nesse aspecto, a valorização da inteligência como matéria-prima se consolida por meio da promoção do acesso qualificado à gestão de tecnologias digitais. A geração de conteúdos descentralizados, portanto, mais do que uma estratégia econômica, é o campo mais fértil para a experimentação de arranjos sociais inteiramente originais para participação política.

A questão da interatividade entrou definitivamente na pauta de discussão. Não raro, pesquisadores desavisados, produtores afoitos e políticos de plantão costumam confundir a retórica do consumo, proposta pela indústria do audiovisual digital, com a questão filosófica da inclusão social por meio das tecnologias da interação.

A inclusão tecnológica no universo do audiovisual interativo implica superar, de modo profundo, a condição passiva de telespectador para a

\footnotetext{
${ }^{5}$ Sobre esse tema confira: FUNTTEL. Projeto de Implantação do Sistema Brasileiro de Televisão Digital: modelo de implantação. Disponível em <http://www.finep.gov.br/>. Acesso em: 20 out. 2006.
} 
condição ativa de usuário co-autor da informação que consome.

Não será fácil implantar o sistema interativo, visto que a televisão se consolidou a partir de políticas públicas de comunicação (e de educação e cultura também) que tratam o público como consumidor. Essa condição, embora inclusiva no sistema de distribuição, é excludente do sistema produtivo. Em termos políticos, é conveniente que as platéias sejam mantidas ignorantes acerca dos modos de produção daquilo que consomem.

Essas políticas são o resultado, ao longo do século XX, da somatória de alguns fatores estratégicos, dentre eles a associação de setores da indústria, dos anunciantes, de produtores, artistas, cientistas e críticos com o poder de Estado centralizador, antidemocrático na essência (nos modos de produção), embora liberais no discurso (nos meios de consumo).

ramo dos anunciantes encontrou na televisão meio fértil para difusão de seus produtos e serviços, impondo socialmente modos e estilos de vida. Privatizar o espaço social da produção de audiovisual foi a sutil estratégia de exclusão tecnológica e, em contrapartida, o substrato para as grandes polêmicas sociológicas e partidárias ao longo do século.

A indústria de eletrônicos floresceu em torno da produção de equipamentos, alimentada pelo vertiginoso aumento da capacidade de soluções das pesquisas de base e aplicadas. Muitos ramos das engenharias elétrica, eletrônica e de telecomunicações, da matemática e da física, dentre outras importantes áreas das ciências exatas, especializaram-se no desenvolvimento da imagem técnica promovida pela comunicação audiovisual.

A imagem técnica, nesse contexto, deve ser considerada como um paradigma de produção e um princípio de representação simbólica articulador do pensamento contemporâneo e não apenas um subproduto da pesquisa tecnológica.

acúmulo de conhecimento filosófico e científico nessa área do saber pode ser caracterizado pela sofisticação das possibilidades tecnológicas da formas eletrônicas de representação de mundo. Durante os anos 1960, alcançou-se o domínio do texto em máquina elétrica. Nos 1970, as imagens e a música incorporaram os efeitos eletrônicos. Nos 1980 se desenvolveu a personalização do computador e o domínio sobre o movimento nas mensagens multimídia.
Os anos 2000 conquistaram a interatividade por meio da teleconferência audiovisual. Não está longe, por fim, a conquista da telepresença. Com ela, o usuário poderá criar uma interface física multidimensional entre linguagens e pessoas apartadas no espaço geográfico.

Contudo a radicalização do princípio filosófico da interatividade tem sido diluída pela indústria do audiovisual, a partir de certas estratégias de publicidade e propaganda que procuram esvaziar seu sentido mais geral. A interatividade permite a presença do público na construção das mensagens, como co-autor da obra. Essa capacidade política vem sendo diluída pela indústria da cultura ao propor apenas a participação do público em detrimento da interação. A mídia comercial, por meio de um artifício discursivo, adotou o termo interatividade para designar a estratégia de estímulo-resposta do público, no máximo, na condição de consumidor participante (opinativo), em substituição à perspectiva da comunicação multilateral.

A maior novidade posta na cena da cadeia produtiva do audiovisual é a consideração da existência de um interlocutor inteligente e capaz de responder prontamente ao diálogo. A presença de outras vozes da alteridade - na construção da narrativa, cuja participação deve ser entendida como dimensão tecnológica (e também filosófica, ética e estética) da linguagem, altera as principais noções sobre as técnicas e ferramentas de comunicação convencional.

Com a possibilidade da participação do público na obra, em conseqüência, o autor há de imaginar - e realizar ponto por ponto - contextos, ambientes, espaços e estruturas dramáticas onde a história acontece prevendo a participação física desse público no desenrolar dos acontecimentos da mensagem (Berenguer, 2006)

Com o princípio da interatividade, o público terá acesso às ferramentas de representação que desencadeiam possibilidades estéticas, éticas e filosóficas antes inimagináveis no âmbito da linguagem audiovisual convencional. Essas novidades estão centradas no conceito de síntese de imagens virtuais e sua atualização, por parte do público, nas telas multifuncionais da hipermídia.

A interatividade na comunicação digital, entretanto, descortina dois cenários políticos contraditórios sobre a questão do acesso aos meios. $\bigcirc$ primeiro cenário é o da exclusão do conjunto dos 
produtores potenciais, dado que o modelo de comunicação social centralizada resulta na "propriedade" privada da geração de conteúdos. A questão do acesso, portanto, passa pela regulamentação de mecanismos de incentivo às atividades produtivas. $\bigcirc$ que está em jogo nesse primeiro cenário são as forças do capital financeiro.

O segundo cenário é o da institucionalização generalizada da convergência dos meios de comunicação digitais, o que exige coerência normativa às políticas públicas. Uma lei abrangente para o setor, contudo, deve ser o resultado de um amplo debate sobre as questões do monopólio da opinião, sobre a socialização dos meios e a gestão de fato de um sistema público de comunicação no país. Afinal, o direito de produzir antecede o de difundir. $\bigcirc$ que está em jogo nesse segundo cenário são as condições para liberar as forças do capital cultural.

As iniciativas de parcerias do setor público com o privado para incrementar os investimentos na economia criativa deveriam ter como conseqüência a partilha de experimentos de geração de conteúdos com o conjunto dos agentes hoje excluídos do processo. Afinal, quando se discute o financiamento público da comunicação social, deve-se considerar que isso implica questões éticas mais gerais e não somente as mercadológicas em particular. Quando se debate o que é mais interessante para as pessoas, do ponto de vista da geração de cultura, o modelo de gestão tem que, necessariamente, incluir as pessoas na tomada de decisões. Daí a necessidade de se proceder não apenas no campo dos negócios, mas, associado a ele, desenvolver tecnologias sociais de inclusão, interação e fruição participativa na geração descentralizada e social dos conteúdos (Paulo, 2004).

A questão da regulamentação da comunicação interativa como política pública é, sobretudo, o desenho de um projeto de sociedade possível. Há que se considerar que a própria linguagem digital já se constitui como ferramenta de gestão de conhecimento e plataforma de organização dos processos e produtos de comunicação. Centrar esforços na questão da crítica aos conteúdos dos meios é, de certa forma, desconsiderar que o projeto sociológico, os processos de produção e reprodução e os produtos audiovisuais digitais se constituem, eles próprios, como campo teórico articulador dos atuais mercados de trocas simbólicas. Conseqüentemente, as configurações científicas, os liames intelectuais, as experiências artísticas e os fluxos econômicos decorrentes do uso extensivo de plataformas digitais articulam os conteúdos dos meios de comunicação social e não ao contrário (Winck; Lemos; Dimantas, 2003).

Enquanto as ciências humanas focalizam temáticas referentes dos conteúdos ideológicos das mensagens, isto é, ao consumo extensivo da comunicação, as ciências exatas, por meio do desenvolvimento das tecnologias da linguagem audiovisual interativa, estão propondo um novo paradigma científico, tanto para a produção quanto para a circulação de saberes e práticas, traduzidos em marcas e patentes como propriedade intelectual.

Não se trata de uma questão meramente tecnológica ou reduzida à pauta de discussão política ou econômica convencionais. Estamos tratando de um fenômeno existencial profundo. Trata-se de um modo de vida novo, em gestação enquanto fenômeno gnosiológico mais amplo. Nesse aspecto, a necessidade de expressão por meios audiovisuais e a inclusão política para realizá-la devem ser pautadas como necessidade básica do ser humano, tal como foi (e é) considerada a alfabetização.

Devemos levar em conta o fato de que não existe nenhum obstáculo conceitual, nem em matéria de hardware nem de software, tampouco de público, para a probabilidade de se chegar a um tipo de audiovisual sem as limitações atuais, onde se desenvolvam mensagens verdadeiramente comutativas, proponentes de um novo de design de relações sociais mais próprias à efetiva interlocução (Castells, 1999).

Contudo os objetivos de disseminação das experiências criativas para TV digital entre as comunidades excluídas, por certo, não atendem aos interesses dos grupos econômicos detentores das concessões de canais de TV, tampouco aos políticos que se beneficiam dessa distorcida realidade centralizadora.

Embora as tecnologias envolvidas na realização de audiovisuais sejam fáceis e de custos cada vez mais acessíveis, sofrem a mística, implantada pela indústria da comunicação, da inacessibilidade do mundo das grandes estrelas e personalidades do show business. Ver-se na TV e reconhecer-se nela é a questão de fundo que perpassa boa parte das discussões sobre sociologia dos meios de comunicação e, em especial, as propostas 
de políticas culturais alternativas ao modelo consagrado.

Soma-se aos conceitos e preconceitos sobre o mundo da TV outro agravante para a implantação da TV interativa em larga escala: a tradicional consideração de que a cultura popular tem qualidade duvidosa, mesmo sabendo-se, todavia, que grande parte dos conteúdos da indústria da comunicação são fruto da apropriação dos conteúdos da cultura popular, adaptados ao "gosto" do público médio (Tiriba, 2004).

Superar a histórica política de cultivar a baixa auto-estima dos realizadores populares, a sistemática falta de representatividade dos produtores e a incapacidade organizacional para superar esses obstáculos são tarefas mais difíceis do que se implantarem políticas de inclusão propriamente ditas, sem levar esses condicionantes em conta.

\section{Que projeto de sociedade promete o audiovisual interativo?}

A TV tradicional articulou-se a partir do conceito de grade de programação, organizada por horários fixos de difusão em fluxo contínuo. Esse padrão de distribuição derivou para políticas públicas capazes de configurar a linha de produção da cadeia produtiva, formatar hábitos de consumo e, especialmente, organizar socialmente o fornecimento de informações e o lazer.

No paradigma convencional, os relatos audiovisuais têm características técnicas, artísticas, culturais, sociais, econômicas e políticas bem distintas do paradigma interativo. Historicamente a TV convencional é feita para ser industrializada, como mercadoria da indústria da cultura. A mensagem vem pronta para o consumo, não permitindo nenhuma interferência direta do público nos rumos da narrativa. As mensagens da TV convencional fazem predominar a opinião soberana do autor sobre quaisquer opiniões que os consumidores possam vir a ter.

As mensagens são organizadas de forma a promover um modo de compreender o mundo cuja predominância é a do herói sobre o vilão. Eles se articulam numa linha coerente de tempo, com início, meio e final, onde a idéia de progresso sempre ruma para um vínculo que resulta em favor do herói. Com essa estratégia ideológica, a indústria da cultura busca estabelecer um imaginário (ou ideário) no qual os motivos do herói são qualitativamente superiores aos motivos do vilão. Se estendermos o conceito aos produtores de narrativas, a supremacia do autor sobre o público, enquanto fundamento ético das narrativas convencionais, delimita o campo entre os que têm algo a dizer e aqueles que se reduzem a consumir discursos prontos (Winck, 2007).

A grande maioria dos estudos sobre as temáticas emergentes concorda que o diálogo interativo com a tela audiovisual digital faz da conversação eletrônica uma experiência radicalmente diferente do que antes era com o livro, o cinema ou com a TV convencional.

O sistema de comunicação no qual a TV interativa se insere, na contramão do padrão convencional, organiza-se a partir do conceito de arquitetura da informação como o acesso simultâneo a determinados textos, imagens e sons de modo cooperativo, o que resulta na partilha de informações numa mesma rede de comunicação. Assistir à TV interativa significa manipular diversas informações simultâneas até então desarticuladas. Algo como ter acesso a um politexto, multidimensional, expresso em suporte multimídia. Há que se considerar, entretanto, que a comunicação interativa, embora possibilite a equidade tecnológica entre os produtores e receptores, não garante a equidade política entre os diversos capitais culturais envolvidos na realização e difusão dos conteúdos.

Deve-se levar em conta que a complexidade da geração de conteúdos interativos para o sistema de TV digital envolve, pelo menos, dois grandes complicadores: o primeiro diz respeito à gestão da cadeia produtiva propriamente dita, a qual envolve múltiplas áreas do conhecimento e centenas de áreas profissionais, atuando coordenadamente na consecução de uma obra audiovisual. Os capitais culturais mobilizados para a realização de uma peça audiovisual provêm de múltiplos agentes, todos submetidos ao capital financeiro centralizado. $\bigcirc$ segundo aspecto, mais sutil, é a superação da divisão social do trabalho intelectual que aparta os autores dos realizadores, no interior da cadeia produtiva do audiovisual e, conseqüentemente, impede a experimentação da interatividade como fenômeno social mais amplo.

As mensagens interativas permitem que $\mathrm{O}$ público dê sua opinião, com a possibilidade de alterar os rumos internos da mensagem. Os produtos culturais, 
mais abertos à interferência pública, ao invés de buscarem a aprovação deste ou daquele argumento, promovem a possibilidade do debate de argumentos e a necessidade de consenso temporário (Bey, 2001).

No sistema de TV convencional é dada ao público a falsa expectativa da participação pelo voto, em detrimento da articulação e decisão de outras soluções possíveis, da construção de outro conjunto de argumentos que resolveriam o problema noutra ordem ideológica, não prevista inicialmente no roteiro.

As mensagens interativas dão liberdade para a construção dos rumos da mensagem. Nelas o público deixa de participar como eleitor e passa a se comportar como autor ou, pelo menos, como agente, participando ativamente das técnicas de produção e difusão das mensagens. As mensagens da TV interativa são de múltiplas direções (um para todos, todos para todos, todos para um etc.). São mensagens multilaterais, nas quais o público pode acrescentar sua informação ao conjunto das mensagens disponíveis. A promessa do audiovisual interativo, entretanto, é dar lugar ao público o acesso à produção de conteúdo. A decisão de o que fazer com a informação passa a ser problema social, não mais particularizado à mesa dos concessionários dos meios.

Embora não se tenha um modelo estabelecido, é possível que as mensagens apresentem os problemas (ou premissas dramáticas), cabendo ao usuário articular soluções possíveis, como uma obra aberta que só possui meios; os finais dependem da expectativa de uma assembléia virtual de co-autores interconectados em rede. E isso não é teoria, pois em termos conceituais a questão já está potencialmente resolvida nas tecnologias digitais. É política de comunicação.

A interatividade, para se consolidar como política de inclusão cultural, carece de tecnologias criativas e tecnologias sociais voltadas para a realização da comunicação no sentido mais profundo do termo (Cattani, 2003).

Ainda carecemos de experimentos sociais consistentes para definir qual o modelo de navegação em rede mais apropriado para o caso da nossa TV interativa, dado que as diferenças entre os sistemas são abissais, sobretudo no que se refere à questão das interfaces de linguagens, de meios e de modos de produção e acesso.

A interatividade no audiovisual permite a navegação aleatória no bando de dados e a capacidade de intervir nele, no sentido de alterá-lo de tamanho e natureza, licenciando a autonomia de escolha, a possibilidade de recomposição criativa de fragmentos de informação por parte do conjunto de usuários.

Os equipamentos admitem compartilhar conteúdos da rede de computadores, por uma conexão sem fio, com a TV doméstica, pavimentando o caminho para interatividade em plataformas com múltiplos significados e processos "veja-e-sinta", "decida e publique", "interaja e reaja", "consulte e compare" etc.

A inclusão no mundo digital, por intermédio das telecomunicações audiovisuais, pode ser observada pelas diferenças de potencialidades entre os dois sistemas de difusão de TV. Por meio da TV interativa será possível, por exemplo, situações em que um paciente possa consultar seu médico em tempo real, à distância. Por meio desse serviço, o consulente poderá realizar um pré-diagnóstico, feito pelo computador do consultório, mediante perguntas e respostas na sua tela de TV e chegar à prescrição de medicação e tratamento virtuais. A depender do diagnóstico, o paciente poderá dialogar com médico numa consulta via teleconferência, colocando-se ambos tela a tela. Por meio da interatividade, o usuário poderá obter um quadro completo, em múltiplos suportes, do seu estado clínico, fazendo aumentar seu conhecimento acerca de si próprio e do sistema de interação a distância. Nesse exemplo, os médicos, detentores de capital cultural, e geradores de recursos econômicos por meio da comunicação social, passam a figurar como trabalhadores das indústrias criativas.

A experiência da telepresença, somente possível no sistema digital, abre caminho e desdobra-se em qualquer outra situação, seja ela de natureza educativa, por meio da tele-educação, seja jurídica, por meio de fóruns virtuais ou postos de assistência ao contribuinte, de natureza científica, pela troca de conhecimento em rede ou de natureza cultural, pelo intercâmbio de capitais culturais entre os mais diversos agentes sociais (Razeto, 2002).

foco da discussão sobre a democratização do acesso à economia criativa, portanto, ganha mais nitidez quando se aborda a questão pelo viés do método possível para associar a aplicação tecnológica ao capital social e intelectual, tendo como perspectiva o investimento público, no âmbito local e regional, no 
trabalho e na prestação de serviços de nossos profissionais liberais, intelectuais, cientistas, artistas, produtores culturais, professores e demais trabalhadores que manufaturam o pensamento, saberes e práticas no desempenho de suas atividades.

Nessa discussão, deve-se levar em conta que a cadeia produtiva do audiovisual abrange tanto um conceito e um método quanto um estilo de vida, nos quais as principais características são gerar propriedade intelectual e bens imateriais de consumo. $\bigcirc$ novo modelo de comunicação, portanto, deve estar focado na produção, distribuição e acesso público aos saberes e práticas comuns em larga escala, diferente do modelo centralizador atual.

Dessa forma, entra na pauta da geração de conteúdos para o sistema de TV digital o desenvolvimento de programas de formação e capacitação cultural, o apoio à elaboração de novas metodologias estatísticas e a recolha de dados confiáveis sobre as atividades culturais interativas e seu impacto econômico e, sobretudo, o fomento à cooperação técnica e à transferência de tecnologias. Além disso, entram em foco as questões da disseminação de conhecimentos, a partilha de experiências nas áreas cultural e educativa que explorem o potencial dos elementos da cultura local e o apoio às culturas tradicionais, no sentido de incrementar prioritariamente os produtores locais e regionais. Afinal, trata-se da cadeia produtiva que coloca a geração de criatividade, de idéias e de cultura como matéria-prima de seu processo de produção e trabalho.

Mais complicado do que isso, nesse ínterim, é refletir sobre o modo de produção que possa romper com o domínio da informação "pronta" para o consumo tedioso, modelo hegemônico que nubla e mascara o fascínio da descoberta, o êxtase do saber-fazer e a emoção da criação partilhada, como fundamentos da sociedade do conhecimento.

\section{REFER Ê NCIAS}

BEY, H. TAZ: zona autônoma temporária. São Paulo: Conrad, 2001.

BERENGUER, X. Promesas digitales. Disponível em:: <http:// www.iva.upf.es/ berenguer/textos/promessas. html>. Acesso em: 20 out. 2006 .

CASTELLS, M. A sociedade em rede: a era da informação: economia, sociedade e cultura. São Paulo: Paz e Terra, 1999.

CATTANI, A. (Org.). A outra economia. Porto Alegre: Veraz, 2003.

GUERRA, P. A. Socioeconomía de la solidaridad. Montevideo: Nordan, 2002.

MACHADO, A. A televisão levada a sério. São Paulo: SENAC, 2000.
PAULO, A. (ed.). Tecnologia social: uma estratégia para o desenvolvimento. Rio de Janeiro: Fundação Banco do Brasil, 2004.

RAZETO, L. Las empresas alternativas. Montevideo: Nordan, 2002.

TIRIBA, L. (org.) Trabalho e educação: arquitetos, abelhas e outros tecelões da economia popular e solidária. Aparecida: Idéias e Letras, 2004.

WINCK, J. B. Quem conta um ponto aumenta um ponto. o design do audiovisual interativo. Rio de Janeiro: Garamond, 2007.

WINCK, J. B.; LEMOS, M. A.; DIMANTAS, H. Os intelectuais e a cibercultura: além de apocalípticos e integrados. Revista do Instituto Brasileiro de Análises Sociais e Econômicas (IBASE), p.6-1 1, 2003. 